\title{
International Journal of Agriculture Extension and Social Development
}

Volume 4; Issue 2; Jul-Dec 2021; Page No. 110-116

Received: 03-05-2021

Accepted: 16-06-2021

Indexed Journal

Peer Reviewed Journal

\section{Rooftop garden an organic farming to grow uncontaminated vegetable improved food quality and food security in Bhubaneswar City, India Kartik Chandra Sahu ${ }^{1}$ and Dr. Mahendra Kumar Satapathy ${ }^{2}$}

${ }^{1}$ Ph.D., Research Scholar, Department of botany, Utkal University, Bhubaneswar, Odisha, India

${ }^{2}$ Dean from Regional Institute of Education, (National council of Education Research and Training) NCERT, Sachivalaya Marg, Bhubaneswar, Odisha, India

DOI: https://doi.org/10.33545/26180723.2021.v4.i2b.110

\begin{abstract}
The trend of growing vegetables on rooftop promotes agricultural aspects in Bhubaneswar city of India. Rooftop gardens become an important part of urban agriculture are recent recurrent and alternative establishments to grow vegetables. Rooftops create spaces to vegetable production and thereby create opportunities for agricultural incorporation into urban communities, However vegetable production activities on rooftops are limited due to multiple challenges that need to be addressed before widespread implementation takes place. Rooftop agriculture can improve various ecosystem services, enhance the biodiversity of urban areas and reduce food security. Food production from rooftop gardens will help support and sustain food for urban and provide a rare opportunity to grow food efficiencies in typically unused spaces of the building. As human populations become more urbanized and urban consumers become more interested in local food for their families, the use of alternative agricultural production systems, such as rooftop cultivation technologies will increase. Importance of cultivating vegetables on buildings is a key component of making cities more sustainable and habitable. Rooftops are not the total solution to providing food security but they should supplement other sources of food production in urban areas. In covid-19 rooftop gardens play an important role during scarcity of vegetables. It is an alternative method of urban cultivation and people obtain vegetables from doorstep in safe guard from Covid -19.Rooftop garden gives us pure organic vegetables and is pleasant.
\end{abstract}

Keywords: Rooftop garden, rooftop organic farming, food quality, food security, Covid-19 pandemic

\section{Introduction}

India is regarded as a survivor of the adverse effects of climate change as one of the vulnerable countries. Throughout today's rapidly growing population, the country's leading development issues include poverty alleviation, sustainable development, food security, and environmental management. Whereas, being a densely populated city, Bhubaneswar has surpassed its capacity to carry. In India, the number of low-income consumers in cities is also increasing rapidly due to migration from rural areas to urban areas. Urban agriculture can provide a source of fresh produce for urban residents, a better diet, and substantial budgetary savings to households. Vegetated surfaces have important properties to sound insulation and are often used in urban settings for their potential for noise reduction. It can also build jobs and economic facilities through its backward and forward relations. Rooftop gardens can complement the community's diets by providing fresh produce and a tangible benefit to food production. [Ref-3] With rapid and unplanned urbanization, the incidence of urban deprivation and food security has also increased alarmingly in Bhubaneswar claimed that urban agriculture (UA) contributes to food security by Increasing food supply and improving the quality of perishable food to urban consumers. [Ref-1] It indicated that strong political engagement and sound policy guidance are the preconditions for establishing a supportive environment for RTG. Rooftop garden involves Roof top farming, terrace gardening, balcony Garden, roof kitchen garden, container garden, soil less culture, media culture, aquarium, hydroponics and Aeroponic. This study aims to identify potential for and obstacles to rooftop gardening (RTG) and to explore strategies for promoting food security in Bhubaneswar a smart city of India during Covid -19 .

Study Area: Bhubaneswar [20.270N 85.840 E] is a smart city in India's eastern state of Odisha. It is a smart city declared on 28 January 2016 and also called as temple city and capital of state Odisha. Due to the India declared smart city, smart farming is growing on the rooftop. Farming is one of the interesting cultivation in Bhubaneswar city of India. Bhubaneswar is a densely populated city of India. It contains a large space of roof and the people of Bhubaneswar are very much interested in cultivating rooftop, terrace and balcony farming.

\section{Material and Method}

The relevant information on the subject has been gathered 
from various primary and secondary sources. A questionnaire survey of household Owners and a survey of residents and responsible authorities of selected public and commercial buildings investigated the Viability of rooftop gardening (RTG). In addition, there was also a focus group discussion where participants were invited to discuss the city's rooftop gardening opportunities and issues. For example, NGO people (on providing microcredit), City Corporation Departments Bhubaneswar development authority (BDA), land and house owners (on leasing and enabling tenants to garden) and the general public (on their overall reaction) were asked to express their opinion. [Figure-1]

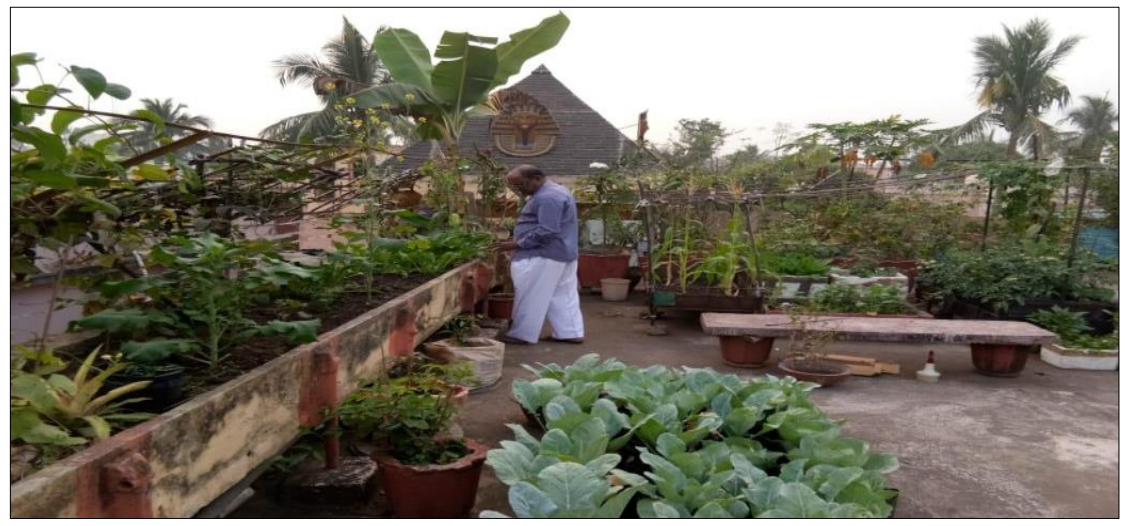

Fig 1: Mr. Maheswara Khilar, Sahid Nagar, Bhubaneswar, Working In His Own RTG.

\section{Types of Green Roof}

The roof of the building has a flat top roof and sloped roof. Apart from that terrace of the building can brow vegetable called terrace garden. Some building has large balcony. Now a days, in some buildings in Bhubaneswar city, many architects practice green roofs, although not very scientifically. [Ref-4] For local plants the roof and other cleaved building plants many of the buildings maintaining for a long time. While green roofing practices in Bhubaneswar apartment buildings are small, there is vast potential to incorporate green roofing concepts in Bhubaneswar city context. According to their use and these are the possible categories of green roofing and rooftop gardening in Bhubaneswar. [Figure-2]
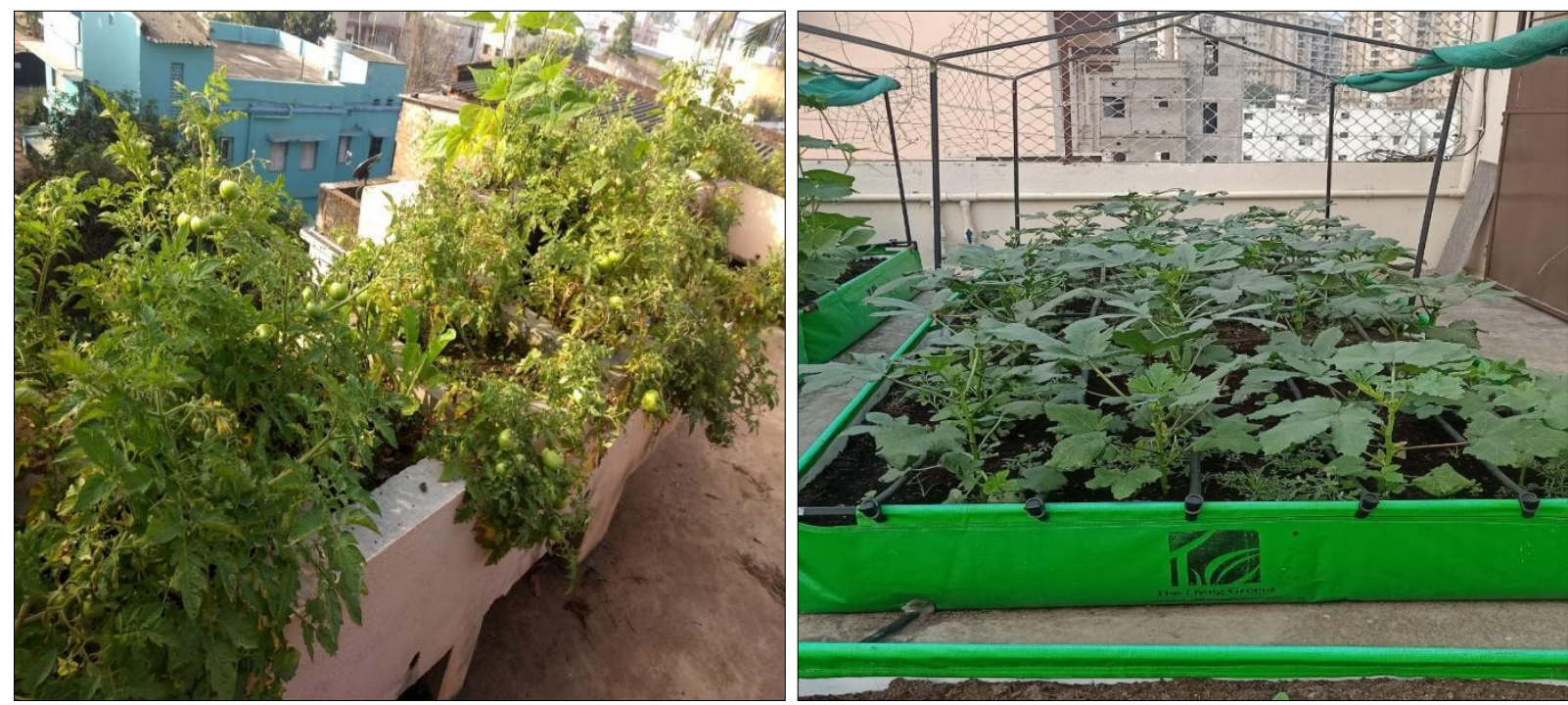

Fig 2: Tomato cultivation in barricade fixed concrete lane and lady finger cultivation in extensive poly container with poly house in Bhubaneswar.

1. Extensive rooftop with barricade lane

2. Extensive with some intensive plantation

3. Plants in fixed and designed container

4. Plants in movable container

5. Movable racks. Intensive green roofs are uncommon in Bhubaneswar practice. Type I, II and III are more generally constructed in the construction phase and these rooftops are regularly maintained. [Ref-13] Typically those users grow Type 'IV and $\mathrm{V}$ roof gardens after the construction. Variety of containers used in roof gardens. These are plastic items like a jar, bag, bottle, dram, tray, protocol, polythene bag, the natural counter belonging to soil pots, bamboo stem, and bowl. [Figure-3] 

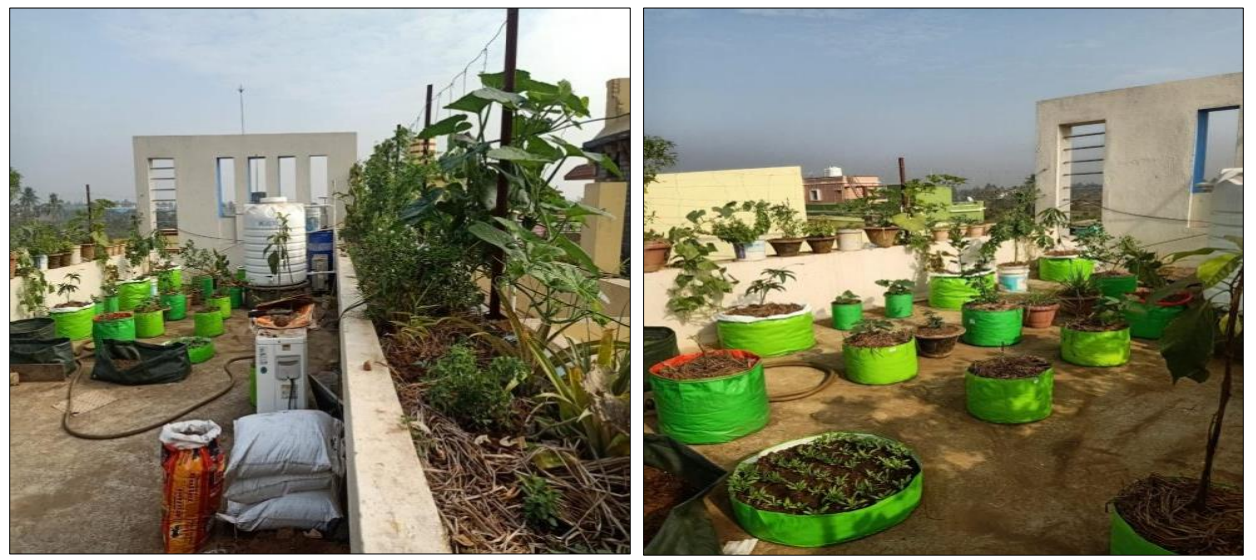

Fig 3: Containers Use in Rooftop Garden in Bhubaneswar.

\section{Fertilizers}

Bio-compost is best for rooftop gardens and container gardens. Bio- fertilizer or organic fertilizer categories as solid bio-compost, media culture, Bio- liquid media. Organic farming is indicated to rooftop farming to obtain pure and fresh food, compost made within the roof from kitchen peels. soilless organic compost made by the cockpit and others in gradient. It is also best for container gardens. Natural bio-liquid media fertilizer made by the urban RTG farmer which has been used as an ingredient for preparation of Bio-media liquid fertilizer. Cows urine and dung, leaves, Kitchen vegetable peels, water, molasses, house waste, and other bio-degradable waste. [Figure-4]
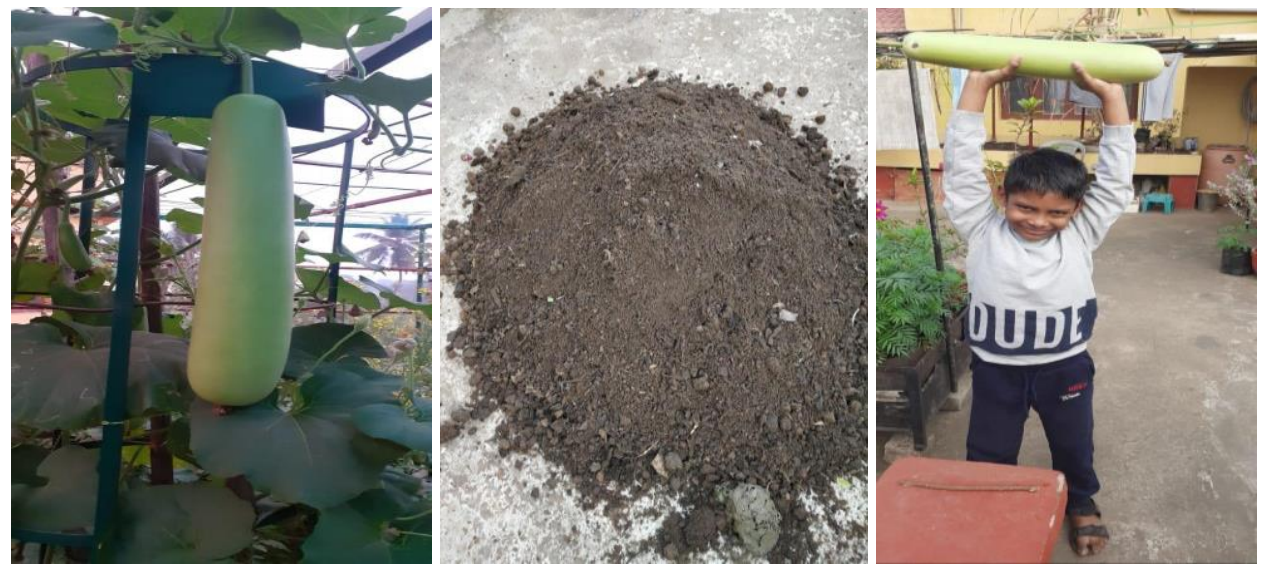

Fig 4: Rooftop Organic Farming Growing Quality Food to Quality Health in Bhubaneswar

\section{Water Supply}

Deeping, pipeline, spray, rainwater management, Irrigation techniques used in rooftop gardens are adopted. [Figure-5].
The rainwater management is performed in the rooftop garden. [Ref-5].
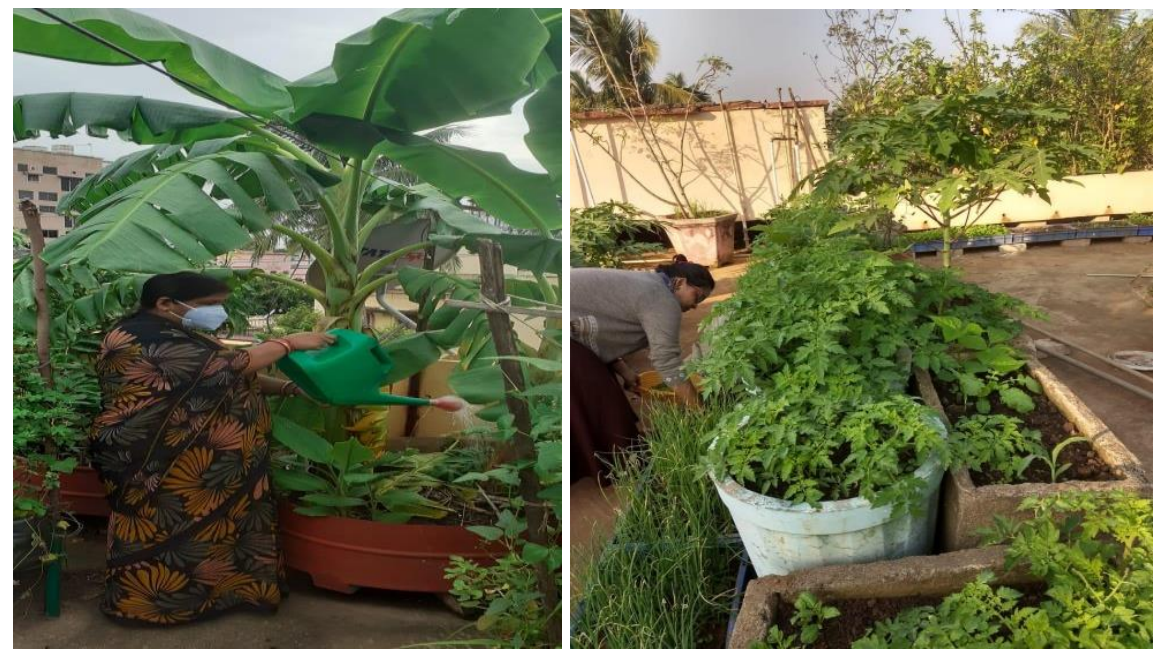

Fig 5: Mrs. Pratibha Khilar Watering His Rooftop Vegetable Garden during Covid-19 


\section{Selection of Plant and Seed}

Around 102 vegetable and 35 fruit varieties are cultivated in a rooftop garden in Bhubaneswar. It is not possible to produce all styles on the rooftop. [Ref-2] Depending on individual household food preferences, availability of seed types that can be grown on the rooftop, Weather, and soil quality, the types and mixes are selected in the region common vegetable and fruits are as Guava, Lemon, Papaya, Grapes, Green Chilli, Pumpkin, Squash, Onion, Garlic, Coriander leaves, Tomato, Mushroom, Leafy vegetables (e.g., Callao, Jute, Leach and Red Amaranthus)and others (e.g Cucumber, Flat Bean, Bitter gourd, Ribbed ground, Ladies foot, Amaranthus, Dhudi, Cowpea, and Brinjal) are usually grown in the food garden. Some families also cultivate spices and plants used for medicinal purposes. [Ref-9]

A baseline survey was conducted from January to June 2020 with a sample of about 9 using a pre-tested semi-structured questionnaire for required data/information on rooftop gardening in Bhubaneswar found that the average yield was higher for several specific vegetables and fruits. [Ref-8]

\section{Economic Benefits from Rooftop Gardening In Bhubaneswar}

A baseline study on rooftop gardening in Bhubaneswar stated that the gross return was obtained from all vegetables and fruits produced in the current RTG's in Bhubaneswar city areas as 'Mt 2686 per year. [Ref-6] The highest gross return came from fruits like Mt. 1486 and vegetables as Mt.12001. Apart from that huge amount of flower production takes place from RTG of Bhubaneswar. Solid waste management, ecosystem service, green family restaurant, Entertainment, family spends leisure time, conservation of flora and fauna. [Figure-6].

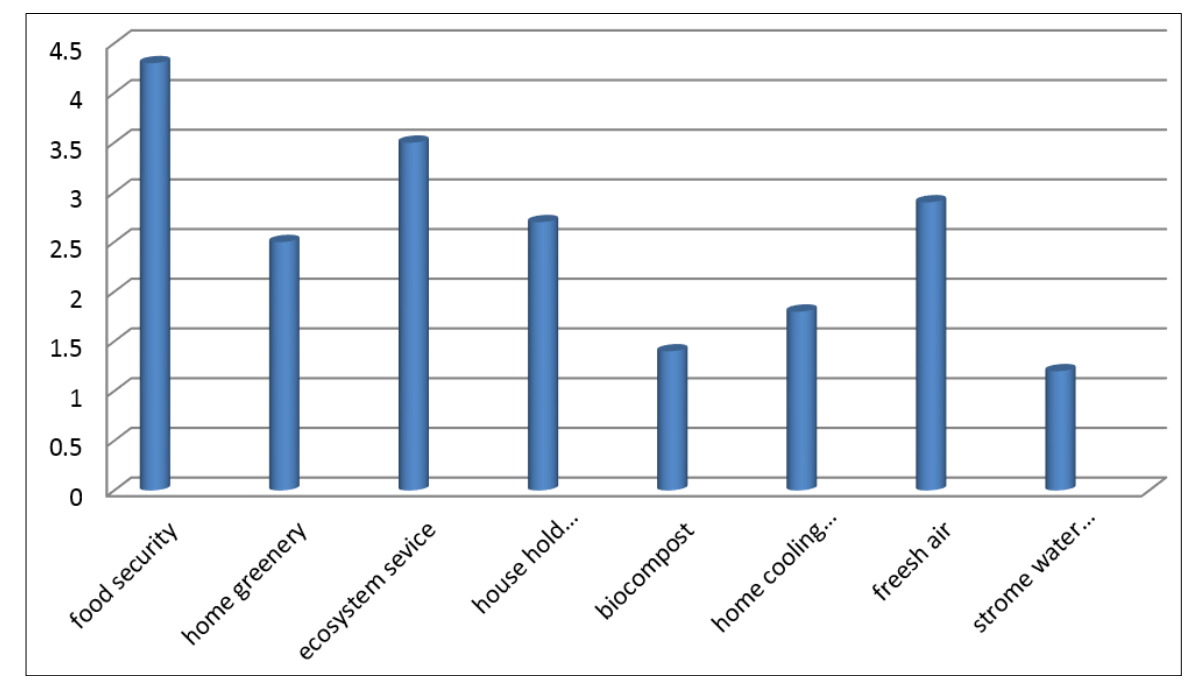

Fig 6: Opportunity of Rooftop Garden (0.5 scale)

A study conducted by Kartik Chandra Sahu stated that the food production value from the rooftop farming of the practitioner of Sahid nagar area is estimated to be between Metric ton Mt. 445,466.79 and Mt. 1538,267.936 i.e. rupees 5000 to 10000 per month which fulfill the basic need of a 56 members family. [Ref-14] The garden mostly produces mixed fruits and vegetables, so the total value of production is likely to be at the lower of this range (around Mt.
243,258.79.Again, the food production value From the rooftop farming of the practitioners of Nayapalli area is estimated to be between Mt. 210,346.76 and Mt. $23,105,803,50$. The garden produces fruits, vegetables and also lettuces, flowers, so the total value of production is likely to be in the middle of this range around Mt. 1,148,233.39. [Table-1]

Table 1: Survey of economic benefits of ten important vegetable cultivation in RTG of Bhubaneswar for the year 2020.

\begin{tabular}{|c|c|c|c|c|}
\hline SL/NO & Name of Vegetable & Botanical name & Production Rate M.Tons/Year & Average income in rupees/year \\
\hline 1 & Tomato & Solanum lycopersicum esculentum & $70552 @ \mathrm{Rs} \mathrm{40/kg}$ & $28,22,08,000$ \\
\hline 2 & Brinjal & Solanum melongena & $38247 @ \mathrm{Rs} \mathrm{30/kg}$ & $11,47,41,000$ \\
\hline 3 & Lady finger & Abelmoschus esculentus & $44622 @ \mathrm{Rs} \mathrm{40/kg}$ & $17,84,88,000$ \\
\hline 4 & Cauliflower & Brassica oleracea botrytis & $28045 @ \mathrm{Rs50/ \textrm {kg }}$ & $14,02,25,000$ \\
\hline 5 & Cabbage & Brassica oleracea capitata & $33246 @ \mathrm{Rs} \mathrm{30/kg}$ & $9,97,38,000$ \\
\hline 6 & Cucumber & Kukumis sativus & $15284 @ \mathrm{Rs} 25 / \mathrm{kg}$ & $3,82,10,000$ \\
\hline 7 & Chili & Capsicum frutescens & $19253 @ \mathrm{Rs} 60 / \mathrm{kg}$ & $11,55,18,000$ \\
\hline 8 & Pumpkin & Cucurbita moscchata & $14062 @ \mathrm{Rs} 20 / \mathrm{kg}$ & $2,81,24,000$ \\
\hline 9 & Bitter gourd & Momordica charantia & $18627 @ \mathrm{Rs} 40 / \mathrm{kg}$ & $7,45,08,000$ \\
\hline 10 & Cow pea & Vigna sinensisi & $21394 @ \mathrm{Rs} 30 / \mathrm{kg}$ & $6,41,82,000$ \\
\hline
\end{tabular}

\section{Common problem of RTGs}

There is an ambivalent relationship between birds and vegetables. Although many birds are important predators of pests in the garden, it has been found that birds often cause disturbance by cutting small plants of vegetables and fruit. The plant leaves make the root unclean so that the roof 
needs to be periodically washed. Another problem is finding plants of good quality. They get plants most of the time from a local nursery. [Ref-7] But sometimes they get discouraged and buy low-quality crops, so they don't get desirable output. In 2013, only one-time assistance was provided from the Department of Agriculture Extension (DAE) project. There is no further support or follow-up to boost their rooftop farming from the state or any other organization. Tenants are typically not interested in garden development. In addition, a professional gardener would be needed if the practitioner wants to expand the garden. Another problem that has been found to hamper the development in her garden by the shadow of the neighboring building. Therefore, the absence of height and (building) density increasing would be a more potential issue it the number of such practitioners increased"

\section{Threats to Rooftop Farming}

It had been discussed during the study of non-practitioners why people did not practice rooftop farming. Most of them said they did not have enough leisure or free time to introduce and take care of the garden. 33.3 percent of people said they were busy with their personal and official work and had insufficient time to spend on gardening or timing. [Ref-11] Lack of technological knowledge also constitutes a constraint not to practice. There are very few ways to acquire knowledge to technology and agriculture. To trained people and provide adequate farming equipment, there is no governmental or private initiative. But $25 \%$ of people say they don't want to learn because they don't have proper knowledge to agriculture. There is also a desire to purchase food items instead to producing them from near-market places. Nineteen percent of people think that buying the required goods from nearby markets or kucha bazaars are easier than growing on their rooftops because time, labor and money are needed. So by spending some money, they feel they can have what they want. Manpower shortages are also limitation. If people want to introduce farming on their rooftop, they need some support, but there is a shortage of experienced and skilled labour to take care of farming in the present condition. 15.5 percent of people believe that having no resources is a concern for them. Only $7.2 \%$ of people replied that they had insufficient space because their root was used for other purposes. Cyclone is one of the most important problem for RTG in Bhubaneswar which obstacles to decrease perception among RTG practitioner. [Ref-10]

\section{Recommendations}

There are no proper initiatives and incentives from the government or any other organizations to boost up and flourish the practice of rooftop farming in Bhubaneswar city. But some NGOs and organizations are initiated to promote rooftop farming as mentioned earlier, incentive activities. Similarly, many policy incentives can also be implemented for India as organic farming by the primeminister of India. Mr, Narendra Modi Ji. There was no provision for including facilities for rooftop farming when any building is designed. Therefore, the provision can be made in BNBC and can be enforced to make rooftop farming compulsory in all new buildings. Additionally, FAR (Floor Area Ratio) or density bonus can be given to people who will practice rooftop farming. This will further encourage the real estate sector to consider rooftop farming in the design of buildings. Moreover, the municipality should provide funds or incentives for those who are currently practicing and those who will practice in the future as by storm water retention due to rooftop farming, the municipality can save a significant amount of money. Also, it the government provides incentives regarding the price of plants and necessary equipment, it may encourage people to initiate rooftop farming. [Ref-12]

There is a lack of information about rooftop farming among Bhubaneswar city dwellers. People are not completely aware of the benefits of rooftop farming. This is mainly because that movement, community and NGO side are not making coordinated efforts on it. Again, many people do not have sufficient technical or farming knowledge on rooftop farming. Proper framing and awareness programs should be initiated by the Government to spread the knowledge of rooftop farming. DAE should be worked more efficiently and should be supportive to make provision of rooftop farming framing regularly through support from NGOS or community organizations. Although most roofs are suitable for gardening, some modifications are always necessary to make it more suitable for rooftop farming. However, if the layout of a building considers rooftop farming from the initial phase so that it can bear the load to plants, soil, etc., this additional modification and additional costs are not required. It should also be planned what plants to be grown and which space of the roof can bear how much of the weight, the size of the drums or tubs, etc. There should also be provision to provide necessary facilities' like water taps in different locations on the root, designated space to plantation, the facility of netting to protect plants and fruit from birds, etc. During the design phase of the houses, all these necessary measures should be considered. Roof dampness is one of the most prominent challenges facing rooftop farming in Bhubaneswar. To save the root from any harmful situation, drums, containers, and tubs can be put over the bricks. IF there are bed systems for vegetables and fruit, the roof will be saved from future damage.

\section{Result}

Food production and consumption in urban areas has become a global concern due to the increasing number of people living in and moving to urbanized living spaces, which challenges food security" Rooftop agriculture enables urban areas to become more sustainable in their resource utilization and to assist residents in improving food security. While growing food on buildings is a component of making cities more sustainable and habitable, green roots are not the total solution for providing cities with food security. If local urbanized farming is to be part of the solution to boost food security in cities, green roofs will have to be used as a place to help increase and maintain food products. Survey 'reveals that out of 5000 households, only $25 \%$ of households are either on roofs, terrace and balconies with gardens, most of them are located in Sahid Nager residential areas. Most of the flat roofs are isolated, with no relation to the adjacent one. People rarely use roots as space for security reasons, although some of them are designed for it. The character of rooftops is different from Bhubaneswar although most of the locality is very dense and there is a lack of open spaces, 
people on the rooftop socialize. Here roof to roof connection and interaction is not possible. Due to the subdivisions of

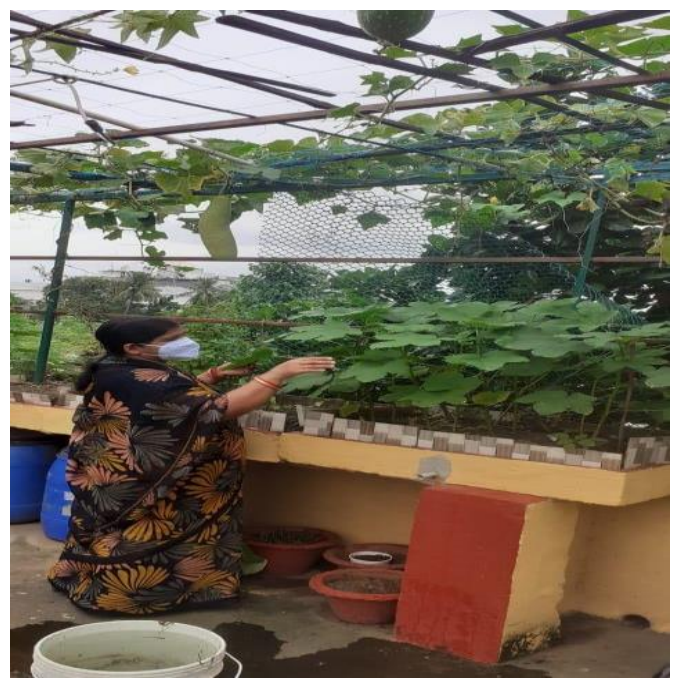

Figure-7: Mrs. Prativa Khilar and Mr. Ekadasi Nandi Working in RTG at Bhubaneswar.

\section{Discussion}

The population and building of Bhubaneswar city is growing higher to higher, the demand for food and expenditure on food is also increasing But the resource is scarce as agricultural land is converted to residential, commercial or industrial land uses. It reduces the possibility of increasing more and more agricultural food products. Again food contamination such as harmful chemical usage to ripe fruits, hazardous or inorganic fertilizer and pesticide use to increase production, etc. In these circumstances, to solve these problems and find a way out, initiation of rooftop farming can be a possible and potential solution. Rooftop farming can help to meet food demand by supplying fresh and hygienic food products, reducing household expenditure for buying vegetables and fruit, saving cost for the municipality by storm water retention, creating a healthy atmosphere by improving air quality and absorbing carbon from the air and lessening the impact of climate change. But this is not possible to implement on a large scale without government provision. But other cities can also practice and may get similar benefits. Other countries that have a scarcity of cultivable land like Bangladesh can also practice rooftop farming to increase greenery and fresh food supply by following the farming method. Any further work such as measuring the benefits of rooftop farming in local, regional and national contexts, standardizing the constant factors of monetary valuation, developing a replicable rooftop farming model is possible with the help and guidance of this report.

\section{Conclusion}

As the population of Indian cities are growing higher and higher, demand for food and expenditure on food are also increasing but the resource is scarce as agricultural land is converted to residential, commercial or industrial land uses. Thus it reduces the possibility to grow more and different agricultural food products. Again food contamination such as harmful chemical and inorganic fertilizer and pesticide usage to increase production etc. is increasing at an alarming rate. In this circumstance, to solve these problems and find a way out, initiation of growing vegetables on the plot, distances between roofs are significant. [Figure-7]

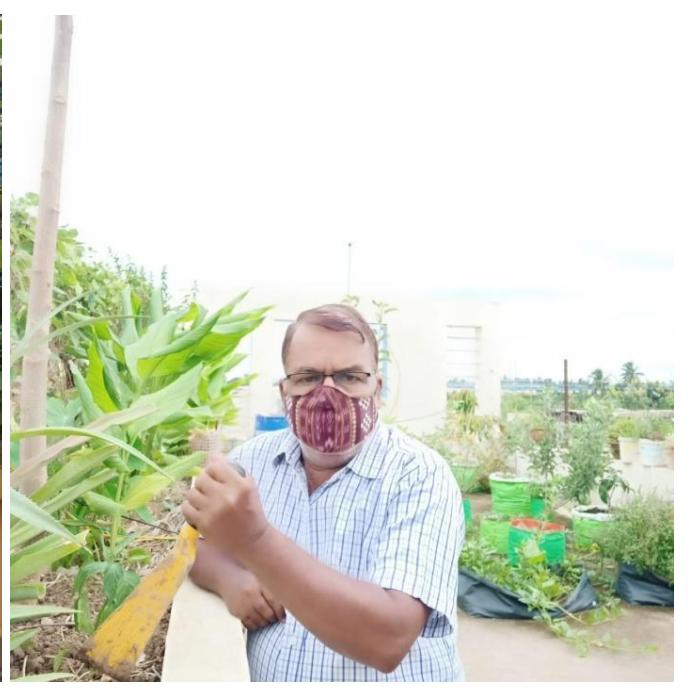

rooftop can be a possible and potential solution. Rooftop vegetable farming can help to meet food demand by supplying fresh and hygienic vegetables, reducing household expenditure for buying vegetables, and creating a healthy atmosphere by improving air quality and absorbing carbon from air and lessening the impact of climate change. Nowadays rooftop gardens grow very rapidly because of the bad influence of covid-19 protocol. Rooftop farming is implemented in each and every city and town of India. Bhubaneswar is one of the smart cities growing rooftop farming successfully. They have a safe guard of opportunity obtained from rooftop gardens. Pure chemical free fresh vegetables and fruits are easily cultivated from rooftop gardens.

Methods-: Not Applicable
List of Abbreviations-: Not Applicable

Declarations

Ethics approval and consent to participate-Not applicable Consent for publication-Not applicable

Availability of data and material-Not applicable

Competing interests-Not applicable

Funding-Not applicable

Author contribution-Not applicable

\section{Acknowledgements}

I would like to thank the following people who have helped to make this research paper possible

First and foremost, I would like to thank my guide Dr.Mahendra Kumar Satapathy. Regional Institute of Education, Bhubaneswar for guiding me to prepare this research paper. I would like to thank my committee for taking the time to listen and guide me along the way.

I would also like to thank Dr. Petikam Srinavas who supervised one of the research studies of the thesis for sharing his knowledge and research interest, and for introducing me to the qualitative research work.

Mr. Maheshwar Khilar Thanks a lot for your support, knowledge exchange and guidance during my research stay in Bhubaneswar. 


\section{References}

1. Ackerman K. The potential for urban agriculture in New York City: Growing capacity, food security, and green infrastructure. Urban Design Lab, Earth Institute, Columbia University, New York, 2011.

2. Alaima K, Packntt E, Miles RA, Kruger DJ. Fruits and vegetable intake among urban community gardeners. Nutr Educt Behav 2008;40:94-101.

doi:10.1016/j.jneb.2006.12.003

3. Altieri MA, Companion9x, Canizaras K. The greening of the "barrier: urban agriculture for food security in Cuba Agric Human Values 1999;16:131-140. doi:10.1023/A:1007645304861

4. Allen A. Environmental planning and management of the peri-urban interface: perspectives on an emerging field. environ Urban 2003;15:135-148. doi:10.1177/095624780301500103

5. Angell S, Farriency R, Gasol CCM. Environmental analysis of rainwater harvesting infrastructures in diffuse and compact urban models of Mediterranean climate.int J Life Cycle Assess 2012;17:25-42. doi: 10.1007/s11367-011-0330-6

6. Bianchini F, Hewage K. Probabilistic cost-benefits analysis for green roofs: A lifecycle approach. Building Environ 2012;58:152-162. doi: 10.1016/J.buildenv.2012.07.005

7. Coley D, Howard M, Winter M. Local food, food miles and carbons emissions: A comparison of farm shop and mass distributions approach, food supply a case study on deserts apples. Environ Mange 30:560-76. Policy 2009;34:155-155.

doi:10.1016/J Foodpol.2008.11.001

8. Godfray HCJ, Bedding ion JR, Curt. Food security: the challenge of feeding 9 billion people. Science 2010;327:812-8. doi:10.1126/science. 1185383

9. Kirwan J, Maye D. Food security farming within the UK and the integration of local food systems. J Rural Study 2012;29:91-100. doi:10.1016/J.jrurstud.2012.03.002

10. Kortright R, Wakefield S. Edible backyards: a qualitative study of household food growing and its contributions to food security: Agric Human Value 2010;28:39-53. doi:10.1007-s10460-009-9254-1

11. Orising F, Marchetti L. Exploring the production capacity of rooftops gardens (RTGs) in urban Agriculture: the potential impact on food and nutrient security, Biodiversity and other ecosystem services in the cities of Bologna. Food Sceur 2004;6:781-792. doi:10.1007/s12571/0389-6

12. Safayet M, Arefin MF, Hassan MMU. Present practice and future prospect of rooftop farming in Dhaka city: A step towards urban sustainability. Journal of urban Management 2017;6(2):56-65.

13. Simith VM, Green RB, Siliberange J. The social and spatial dynamics of community food productions: a landscape approach to policy and program development. lands Ecol 2013;28:1415-1426. doi.10.1007/s10880-013-98911-w

14. Wong N, Tay S, Wong R, Long C, Sia A. Life cycle cost analysis of rooftop gardens in Singapore. Building and Environment, 2003, 38(3). Retrieved June 19, 2009, from Science Direct database. 